Ayurlog: National Journal of Research in Ayurved Science

\title{
Benefits of yoga in premenstrual syndrome- a critical review
}

\section{Divya Munishwar ${ }^{1 *}$, Brijesh Mishra $^{2}$}

1. Associate Professor,

2. Professor \& HOD, Email: drbrijeshm74@gmail.com

Dept. of Sanskrit Samhita Siddhant, Shri Ayurveda Mahavidyalaya, Nagpur

*Corresponding author: divyashahu30@gmail.com

\begin{abstract}
-
Objective: The objective of this study is to see in detail the physiological and hormonal changes during the premenstrual phase and the effects of yoga practice in Premenstrual syndrome (PMS) so that, the percentage of females suffering from it benefits of yoga. This is important for tw reasons, firstly because the symptom premenstrual tension is responsible for socioeconomic loss and secondly because associated legal and women's rights issues that have arisen in conjunction with personal accountability during the PMS. ${ }^{1}$
\end{abstract}

Method: A critical review was done from various evidence-based research papers and the subject matter from the classical texts.

Conclusion: Yoga exercise reduces harmful inflammatory secretions which make women with premenstrual syndrome comfortable. Studies in India have shown positive impacts of yoga exercise on women with PMS on decreasing heartbeats, blood pressure, and anxiety.

Keywords: Yoga, premenstrual syndrome, premenstrual tension, critical review

\section{Introduction}

This article reviews the evidence for the effect of yoga in premenstrual syndrome in females. Yoga philosophy and practice were first described by Patanjali in the classic text, Yoga Sutras, which is widely acknowledged as the authoritative text on yoga. ${ }^{2}$ Today, many people identify yoga only with Asana, the physical practice of yoga, but Asana is just one of the many tools used for healing the individual; only three of the 196 sutras mention Asana and the remainder of the text discusses the other components of yoga including conscious breathing, meditation, lifestyle and diet changes, visualization and the use of sound, among many others. ${ }^{3}$

In Yoga Sutras, Patanjali outlines an eightfold path to awareness and enlightenment called Ashtanga, which literally means "eight limbs"., Premenstrual syndrome (PMS) also described as premenstrual tension (PMT) is a symptom complex recognized primarily by cyclic changes associated with ovulatory cycles. It occurs 7 to 14 days prior to menstruation and is more 
frequently encountered in middle aged women. ${ }^{1}$

Premenstrual syndrome significantly alters autonomic function and psychological status of young females. Regular practice of yoga has beneficial effects on both the phases of menstrual cycle by bringing Parasympatho dominance and psychological well-being probably by balancing Neuro-Endocrinal Axis. ${ }^{5}$ A growing body of evidence supports the belief that yoga benefits physical and mental health via down-regulation of the hypothalamic-pituitary-adrenal (HPA) axis and the sympathetic nervous system (SNS). ${ }^{6}$ Commonly in yoga manuals and instructional articles, women are advised to refrain from certain Asanas, such as the inversion postures Sirsasana (headstand) or Sarvangasana (shoulder stand) during menstruation, ${ }^{7}$ whereas in the Ashtanga Vinyasa tradition of Patthabi Jois, ${ }^{8}$ wome are advised to refrain from Asana practice in the first 3 days of menstruation off from practice. $^{9}$

\section{Method}

Previous study shows that there was significant alteration of Autonomic functions and Psychological status in premenstrual phase when compared with postmenstrual phase in young healthy females. $^{5}$ Also, the functioning of Autonomic nervous system during the late luteal phase is altered which could be associated with diverse Psychosomatic and behavioural symptoms appearing during premenstrual phase. ${ }^{10}$ In women with PMS, negative changes start soon after ovulation gradually increasing as the corpus luteum develops, and reach a maximum during the last 5 days of the luteal phase. They decline rapidly once menstruation starts, disappearing within one or two days of ovarian steroids reaching baseline levels. Positive moods are at maximum when preovulatory estradiol reaches its peak. ${ }^{11}$ Evidences indicated that physical and mental health benefits of yoga occur through negative moderation of hypothalamic-pituitaryadrenal axis in association with sympathetic nervous system (SNS). Yoga exercise, negatively, via vagal nerves, regulates secretion of hormones (cortisol, glucose, plasma 's renin, epinephrine and norepinephrine) into the bloodstream which are responsible for body functions. ${ }^{12}$ Yoga reduces the negative effects of induced stress to immune system by regulating positively the adjustment of immunoglobulin A. ${ }^{13}$ Additionally, yoga exercise reduces harmful inflammatory secretions, which make women with PMS, comfortable. Studies in India have shown ositive impacts of yoga exercise on women with PMS by decreasing heart beats, blood pressure and anxiety. 14,15 Yoga plays an important role in reducing stress, reducing sympathetic activity 16,17 increasing parasympathetic activity ${ }^{18}$ decreasing blood pressure ${ }^{19}$ improving sense of well-being ${ }^{20}$ and decreasing anxiety levels ${ }^{21}$

\section{some of the Useful Aasanas in females -}

Pawanmuktasan,

Bhujangasana,

Shalabhasan, Dhanurasana, Vajrasana,

Bhadrasana, Sarvangasana, Halasana, Ardhamatsyendrasana, Makarasana, Shavasana, Vipritakarani,

Suryanamaskara.

\section{Useful Pranayama-}

1. Nadishodhana - to reduce stress and anxiety 


\section{Shitali 22}

\section{Discussion}

Yoga is rapidly emerging in the Western world as a discipline for integrating the mind and body into union and harmony, when adopted as a way of life. Also, yoga improves physical, mental, intellectual and spiritual health. Yoga is an effective method of managing and reducing stress, anxiety and depression and numerous studies demonstrate the efficacy of yoga on mood related disorders. PMS is also one of the mood related disorder. Yoga, a form of mind-body exercise, has become an increasingly widespread therapy used to maintain wellness, and alleviate a range of health problems and ailments. Yoga should be considered as a complementary therapy or alternative method for medical therapy in the treatment of stress, anxiety, depression, and other mood disorders as it has been shown to create a greater sense of well-being, increase feelings of relaxation, improve self-confidence and body image, improve efficiency, better interpersonal relationships, increase attentiveness, lower irritability, and encourage an optimistic outlook on life.

Health care professionals, health educators and the like, need to be aware of the potential of yoga as an important component of a personal wellness plan.

While modern medicine has the ability in many cases to heal physical diseases and alleviate psychological disorders, it is argued that a purely medical approach is far less effective in healing the emotional, intellectual, and personality layers of the human entity. The discipline of yoga offers individuals a timeless and holistic model of health and healing and although it may not result in the complete elimination of physical diseases and/ or adverse conditions from the body it offers a holistic path of healing. There exists an indisputable connection between a person's overall physical and mental health and the inner peace and well-being yoga is designed to achieve.

\section{Conclusion}

Premenstrual syndrome (PMS) is a recurrent disorder that occurs in the luteal phase of the menstrual cycle. It is characterized by intense physical, psychological, and behavioral changes that interrupt interpersonal relationships and disrupt the lives of affected women. Premenstrual syndrome is believed to affect $75 \%$ of women of childbearing age. Because no tests can confirm PMS, the diagnosis should be made on the basis of a patient-completed daily symptom calendar and the exclusion of other medical disorders. The aetiology of PMS is still unknown uncertain, but are likely associated with aberrant responses to normal hormonal fluctuations during the menstrual cycle. ${ }^{23}$

PMS is important for two reasons, firstly, because, the symptoms of PMS are responsible for socio-economic loss and Secondly, because of associated legal and women right issues that has arisen in conjunction with personal accountability during the PMS. ${ }^{1}$ Yoga poses have an inherent ability to balance the endocrine system, metabolism, and neurotransmitters. Regular yoga practice helps prevent pms symptoms in three ways. First it releases endorphins, the body's natural mood elevating compounds says linda Sparrowe, coauther (with Patricia Walden) of Yoga For a Healthy Menstrual Cycle (Shambhala, 2004). Second it calms the central nervous system and increases the flow of oxygenated blood to the reproductive organs, and third, it eases stress and encourages deep 
relaxation, which further mutes the symptoms of pms.

\section{REFERENCES:}

1. V. G. Padubidri, Shirish N Daftary, Shaws Textbook Of Gynaecology, $13^{\text {Th }}$ Edition, ELSEVIER, Pg No 289

2. Lasater J. The heart of Pantajali. Yoga J. 1997;137:134-44.

3. Desikachar K, Bragdon L, Bossart C. The yoga of healing: Exploring yoga's holistic model for health and wellbeing. Int J Yoga Ther. 2005;15:1739.

4. Maehle G. Analoo City, Western Australia: Kaivalya Publications; 2006. Ashtanga Yoga: Practice and Philosophy.

5. Sarita Kanojia, Vivek Kumar Sharma, Asha Gandhi, Raj Kapoor, Ajay Kukreja, Senthil Kumar Subramanian, Effect Of Yoga On Autonomic Functions And Psychological Status During Both Phases Of Menstrual Cycle In Young Healthy Females, Journal of Clinical and Diagnostic Research [serial online]2013 Oct[cited:2016 Sep 8] 102133 - 2139

6. Ross A, Thomas S, The health benefits of yoga and exercise: a review of comparison studies $J$ Altern Complement Med 2010 Jan 16(1):3$12 . \underline{3}$

7. Poses contraindicated for menstruation. Yoga Journal. Online document at: http://www.yogajournal.com/category/ poses/contraindicationsmodifications/menstruation-contra indications-modifications/. Accessed November 7, 2016.

8. Jois SKP. Yoga Mala: The Seminal Treatise and Guide from the Living Master of Ashtanga Yoga. London: Macmillan, 2010.

9. Sweeney M. Astanga Yoga As It Is: Primary, Intermediate, Advanced A \& B Asana and Vinyasa. Yoga Temple, 2005.

10. Matsumoto T, Ushiroyama T, Kimura T, Hayashi T, Moritani T, Altered autonomic nervous system activity as a potential etiological factor of premenstrual syndrome and premenstrual dysphoric disorder Biopsychosoc Med 2007 1:24

11. Backstrom, Torbjorn, et al. "Mood, sexuality, hormones, and the menstrual cycle. II. Hormone levels and their relationship to the premenstrual

syndrome." Psychosomatic medicine 45.6 (1983): 503-507

12. Sterling P. Principles of Allostasis: Optimal Design, Predictive Regulation, Pathophysiology, and Rational therapeutics. In: Schulkin J, ed. Allostasis, Homeostasis, and the Costs of Physiological Adaptation. Cambridge: Cambridge University Press; 2004)

13. Brotto LA, Krychman M, Jacobson P. Eastern approaches for enhancing women's sexuality: mindfulness, acupuncture, and yoga (CME). J Sex Med. 2008;5(12):2741-2748. doi: 10.1111/j.1743-6109.2008.01071.x

14. Chen KM, Tseng WS, Ting LF, Huang GF. Development and evaluation of a yoga exercise programme for older adults. J Adv Nurs. 2007;57(4):432-441.).

15. Michalsen A, Grossman P, Acil A, et al. Rapid stress reduction and anxiolysis among distressed women as a consequence of a three-month intensive yoga program. Med Sci Monit. 2005;11(12):CR555-561.)

16. Dvivedi J, Dvivedi S, Mahajan KK, M ittal S, Singhal A, Effect of '61-points relaxation technique' on stress parameters in premenstrual syndrome Indian $J \quad$ Physiol Pharmacol 2008 Jan 52(1):69-76.

17. Vempati RP, Telles S, Yoga-based guided relaxation reduces sympathetic activity judged from baseline levels Psychol Rep 2002 Apr 90(2):487-94.],

18. Udupa K, Madanmohan Bhavanani A B, Vijayalakshmi P, Krishnamurthy N, Effect of pranayam training on cardiac function in normal young volunteers Indian $J \quad$ Physiol Pharmacol 2003 Jan 47(1):27-33.],

19. Parshad O, Richards A, Asnani M, Im pact of yoga on haemodynamic function in healthy medical 
students West Indian Med J 2011 Mar 60(2):148-52.],

20. Malathi A, Damodaran A, Stress due to exams in medical students--role of yoga Indian $J \quad$ Physiol Pharmacol 1999 Apr 43(2):21824.,10],

21. Rocha KK, Ribeiro AM, Rocha KC, S ousa MB, Albuquerque FS, Ribeiro S, Improvement in physiological and psychological parameters after 6 months of yoga practice Conscious Cogn 2012 Jun 21(2):843-50.10].

22. Vd Vijay Patrikar, Swasthavritta Vigyan , Part 2, Sept 2006, Pg No 107

23. Zaafrane F, Faleh R, Melki W, Sakouhi M, Gaha L. [An overview of premenstrual syndrome] J Gynecol Obstet Biol Reprod (Paris) 2007 Nov;36(7):642-52. [PubMed]

Cite article:

Benefits of yoga in premenstrual syndrome- a critical review

Divya Munishwar, Brijesh Mishra

Ayurlog: National Journal of Research in Ayurved Science- 2019; (7)(1): 1-5 